\title{
A potential role for hepcidin in obesity-driven colorectal tumourigenesis
}

\author{
ELISABETH PHILLIPS ${ }^{1,2}$, RICHARD D. HORNIBLOW ${ }^{2}$, VIKKI POOLE ${ }^{2}$, MATTHEW BEDFORD $^{2}$, \\ DOUGLAS G. WARD ${ }^{2}$, AMANDA J. KIRKHAM ${ }^{2}$, JEREMY TOMLINSON ${ }^{3}$, \\ TARIQ H. IQBAL ${ }^{2 *}$ and CHRIS TSELEPIS ${ }^{2 *}$
}

\author{
${ }^{1}$ Mackenzie Cancer Research Group, Department of Pathology, University of Otago Christchurch, \\ Christchurch 8011, New Zealand; ${ }^{2}$ Institute of Cancer and Genomic Sciences, University of Birmingham, \\ Birmingham B15 2TT; ${ }^{3}$ Oxford Centre for Diabetes, Endocrinology and Metabolism, NIHR Oxford Biomedical \\ Research Centre, Churchill Hospital, University of Oxford, Headington, Oxford OX3 7LJ, UK
}

Received June 14, 2017; Accepted October 9, 2017

DOI: $10.3892 /$ or.2017.6062

\begin{abstract}
The obesity epidemic is associated with increases in the incidence of several types of cancer, including colorectal cancer, and is associated with poor outcomes for patients. Adipose tissue is considered biologically active and represents a plausible link between cancer and obesity due to the many factors that it secretes. In the present study, human adipose tissue was cultured in vitro and predifferentiated adipocyte secretome [preadipocyte (PAS)] and differentiated adipocyte secretome (DAS) were collected. Quantification of interleukin-6 (IL-6), leptin and hepcidin in the DAS medium was compared to the PAS medium. Fold change levels of hepcidin, leptin and IL-6 in DAS $(2.88 \pm 0.28,12.34 \pm 0.95$ and $31.29 \pm 1.89$ fold increases) were significantly higher compared to these in PAS ( $\mathrm{p}=0.05)$. The SW480 colorectal cancer cells were co-cultured with DAS in the presence or absence of leptin, IL-6 or hepcidin inhibitors and cellular viability and proliferation assays were performed. The culture of SW480 with DAS increased the cell proliferation and viability by 30 and $15 \%(\mathrm{p}=0.02$ and $\mathrm{p}=0.03$ ) respectively, which was reversed in the presence of inhibitors. Challenging the SW480 cells with IL-6 or hepcidin significantly elevated colonocyte-secreted leptin $(\mathrm{p}=0.05)$. Challenging the SW480 cells with leptin or hepcidin resulted in elevated levels of colonocyte-secreted IL-6 $(\mathrm{p}=0.05)$. Similarly, challenging cells with either IL-6 or leptin markedly elevated the level of secreted hepcidin $(\mathrm{p}=0.05)$ and this was associated with an induction in colonocyte iron levels in both cases. Collectively,
\end{abstract}

Correspondence to: Dr Chris Tselepis, Institute of Cancer and Genomic Sciences, University of Birmingham, Vincent Drive, Birmingham B15 2TT, UK

E-mail: c.tselepis@bham.ac.uk

*Contributed equally

Key words: iron, cancer, interleukin-6, leptin, adipokine these data revealed that adipocyte-secreted factors can ultimately modulate colonocyte iron levels and phenotype.

\section{Introduction}

A quarter of adults worldwide are classified as obese [(body mass index (BMI), $\left.\left.\geq 30 \mathrm{~kg} / \mathrm{m}^{2}\right)\right]$ (1), with projections that this will increase to a third of all adults by 2020 . Traditionally, obesity has been associated with a plethora of pathologies including type 2 diabetes and cardiovascular disease. Currently, numerous studies have reported evidence of an association between obesity and cancer risk and mortality in some cancers including breast (2), endometrial (3) and colorectal. Meta-analyses have described the risk of colorectal cancer, the third most common cancer in the UK, to be increased by an estimated $25 \%$ in the overweight (BMI, $\left.25-30 \mathrm{~kg} / \mathrm{m}^{2}\right)$ and $50 \%$ in obese men $(4,5)$.

The underlying molecular and cellular mechanisms in obesity-mediated colorectal carcinogenesis are yet to be elucidated, however, accumulating evidence reveals the involvement of hormone-mediated mechanisms in this process. Leptin is a major hormone produced by adipose tissue and circulating serum leptin levels correlate directly with body fat mass. Leptin levels are up to 5-fold higher in obese compared to normal individuals (6). Several studies revealed that elevated leptin levels are associated with increased adenoma and colorectal cancer risk $(7,8)$ and have been reported to induce cellular proliferation, motility and invasiveness in colorectal cell models (9). Furthermore, Fenton et al (10) suggested that leptin drives tumourigenesis through the autocrine production of interleukin-6 (IL-6) a cytokine which is similarly strongly implicated in colorectal tumourigenesis. Studies revealed increased human serum levels of IL- 6 in colorectal cancer patients (11) whilst a murine study revealed that IL-6 signalling is involved in tumour formation and administration of antibodies against IL-6R has been shown to inhibit tumour growth (12). This is further supported by Becker et al (13) who demonstrated that suppression of tumour progression in colon cancer can be achieved by inhibiting IL-6 trans-signalling.

In addition to leptin inducing an increased expression of IL-6, leptin is also able to induce the expression of hepcidin 
(the master regulator of iron metabolism), as demonstrated using an in vitro hepatic model (14). Notably, human studies revealed that direct IL-6 infusion also increases circulating hepcidin levels (15). This is particularly interesting for two reasons. Firstly, dysregulated cellular iron metabolism has been linked with colorectal cancer and studies reveal that cellular iron excess amplifies Wnt signalling (16-21) which is the major oncogenic signalling pathway in the colon. Secondly, obesity is commonly associated with low serum iron concentrations (22-24), with hepcidin likely mediating this obesity-associated anaemia. Hepcidin facilitates its effects by binding to the cellular iron efflux protein, ferroportin and, in the context of normal human physiology, this acts to cause sequestration of iron within the reticuloendothelial system and blocking of duodenal iron transport (25). As well as high body iron levels, inflammation and infection can also induce hepcidin expression through the action of the cytokine IL-6 (25). In addition, systemic levels of IL- 6 are also associated with the low-grade inflammation reported in obese patients (26) and therefore, obesity and adipokines are potentially contributing to, through hepcidin and cellular iron, oncogenic progression in colonocytes.

To date, the mechanism through which these different factors influence colonocyte behaviour and interact in colonic model systems has not been studied. Consequently, to dissect out the role of these factors in obesity-driven carcinogenesis we have recreated an in vitro model whereby we can analyse what omental adipocytes secrete and how the specific analytes, leptin, IL- 6 and hepcidin, function and influence colonocyte behaviour.

\section{Materials and methods}

\section{Patient samples}

Human adipose tissue. Ethical approval for the use of human adipose tissue was provided by the University of Birmingham Human BioRepository Centre (11-068) and all patients provided informed written consents to providing adipose tissue for the present study.

Human serum samples. Patients $(n=163)$ attending Wolverhampton Hospital between 2006-2008 for colonoscopy as part of the National Colorectal Screening Programme had blood collected and stored prior to their examination for colorectal cancer. Of these 163 patients, 73 (45\%) were subsequently identified with neoplasia comprising 51 patients $(70 \%)$ with high risk adenomas and $22(30 \%)$ with cancers. The remaining 90 patients $(55 \%)$ included 39 patients $(43 \%)$ with low risk polyps and 51 (57\%) without abnormalities. Detailed socio-demographics (BMI, smoking, alcohol intake, gender, age, ethnicity), use of non-steroidal anti-inflammatory drugs, comorbidity, symptoms and outcome data were available for all participants. Ethical approval for this aspect of the study was attained by the Black Country Research Ethics Committee 07/H1202/72 Warwickshire Local REC and Birmingham, East, North and Solihull REC. All patients provided informed written consents.

Human adipocyte cultures. Human adipose tissue from the greater omentum of patients undergoing colorectal surgery was collected and following the removal of blood vessels and connective tissue, samples were minced and incubated at $37^{\circ} \mathrm{C}$ for $1 \mathrm{~h}$ in $2 \mathrm{mg} / \mathrm{ml}$ Collagenase II (Sigma-Aldrich, Irvine, UK) in Dulbecco's modified Eagle's medium (DMEM/F-12; Thermo Fisher Scientific, Ashford, UK) with gentle agitation. Following digestion, filtration and centrifugation $(5 \mathrm{~min}$ at $1,500 \mathrm{rpm}$ ) the cell pellets were washed twice in serum-free medium. The preadipocyte cell pellet was then resuspended in growth medium DMEM/F-12 supplemented with $10 \%$ foetal calf serum (FCS; PAA Laboratories, Somerset, UK) supplemented with $100 \mathrm{U} / \mathrm{ml}$ penicillin and $0.1 \mathrm{mg} / \mathrm{ml}$ streptomycin (Thermo Fisher Scientific) and plated into 12-well tissue culture plates (CellBIND; Corning, Cambridge, UK) and incubated at $37^{\circ} \mathrm{C}$ with $5 \% \mathrm{CO}_{2}$ as standard. Upon reaching $70 \%$ confluency the growth medium was removed and $1 \mathrm{ml}$ of serum-free DMEM/F-12 was added overnight. The serum-free medium was collected the following day, centrifuged to remove cellular debris and filtered $(0.22 \mu \mathrm{m})$ and used as the control (PAS) in our subsequent experiments. The cells were then cultured with $1 \mathrm{ml}$ differentiation medium (DMEM/F12 with L-glutamine; PAA Laboratories) containing $10 \% \mathrm{FCS}, 100 \mathrm{U} / \mathrm{ml}$ penicillin, $0.1 \mathrm{mg} / \mathrm{ml}$ streptomycin, $33 \mathrm{mM}$ biotin (Sigma-Aldrich), $17 \mu \mathrm{M}$ pantothenate (Sigma-Aldrich) and $0.2 \mathrm{nM} \mathrm{T3} \mathrm{(Sigma-Aldrich)} \mathrm{which}$ had $167 \mathrm{nM}$ insulin (Sigma-Aldrich), $1 \mu \mathrm{M}$ hydrocortisol (Sigma-Aldrich, UK) and $0.5 \mu \mathrm{M} 1$-methyl-isobutylxanthine (IBMX; Sigma-Aldrich) added prior to use. After four days, the medium was removed and fresh differentiation medium (without IBMX) was applied to the cells until the adipocytes had fully differentiated ( $\sim 14$ days). Once differentiated, the cells were washed and placed in serum-free DMEM/F-12 medium overnight and then the medium was collected [differentiated adipocyte secretome (DAS)] and subsequently used in the experiments.

Culture of colorectal cell lines. Authenticated SW480 colorectal cancer cells (American Type Culture Collection, Manassas, VA, USA) were routinely cultured with growth medium (DMEM; Thermo Fisher Scientific) containing $10 \%$ FCS supplemented with $100 \mathrm{U} / \mathrm{ml}$ penicillin and $0.1 \mathrm{mg} / \mathrm{ml}$ streptomycin. Only cells of low passage $(>\mathrm{p} 25)$ were used in all experiments. For experiments involving the use of adipocyte conditioned medium upon the SW480 cells reaching $70 \%$ confluency, the cells were challenged with either the DAS or with the control (PAS) in the presence or absence of inhibitors of leptin (anti-human leptin/OB antibody MAB398; R\&D Systems, Abingdon, UK) used at a final concentration of $3.2 \mathrm{ng} /$ ml; IL-6 (anti-human IL-6 antibody 500-P26G; Peprotech, London, UK) used at a final concentration of $0.1 \mathrm{ng} / \mathrm{ml}$; or hepcidin (hepcidin antagonist peptide) as previously described by Kaplan et al (27) (RR-FDCITTGYAYTQGLSGSILS-RR; Alta Biosciences, Birmingham, UK) used at a concentration of $1 \mu \mathrm{M}$ and the effect on cellular viability (MTT assay) and proliferation (BrdU assay) was determined, as detailed below. When assessing the effects of the individual proteins (IL-6, leptin and hepcidin) upon the SW480 cells reaching $70 \%$ confluency, the cells were challenged either with leptin (Peprotech) used at a final concentration of $60 \mathrm{ng} / \mathrm{ml}$, IL-6 (Peprotech) used at a final concentration of $10 \mathrm{ng} / \mathrm{ml}$ or human hepcidin (Alta Biosciences) used at a final concentration of $1 \mu \mathrm{M}$ in the presence or absence of the respective inhibitors 
described above. The controls for these experiments included growth medium alone, with and without inhibitors.

\section{Viability and proliferation assays}

MTT [3-(4,5-dimethylthiazol-2-yl)-2,5-diphenyltetrazolium bromide] assay. At the end of the culture period $10 \mu 1$ of MTT (Sigma-Aldrich) $(5 \mathrm{mg} / \mathrm{ml}$ in PBS) solution was added to each $100 \mu 1$ of culture medium/well of the 96 -well plate. The plates were incubated for $3 \mathrm{~h}$, after which the medium was aspirated and replaced with $100 \mu \mathrm{l}$ of DMSO (Sigma-Aldrich) to dissolve the accumulated formazan crystals and then the absorbance was read at $490 \mathrm{~nm}$. Optical densities were used to calculate the percentage of viability with respect to the control.

$B r d U$ proliferation assay. BrdU assays were performed according to the manufacturer's instructions (Roche Applied Science, Burgess Hill, UK). Briefly, the cells were labelled with BrdU, fixed and DNA-denatured with FixDenat solution. The cells were then incubated with anti-BrdU and the immune complexes were detected using a TMB substrate reaction with the reaction product assessed at $490 \mathrm{~nm}$ as described above.

Antibody-array. PAS and DAS were compared using the Human Adipokine Antibody Array 1 (RayBiotech; Insight Biotechnology Ltd., Wembley, UK), which was carried out according to the manufacturer's instructions. The film was then scanned to create an electronic version using Bio-Rad GS-800 densitometry scanner and analysed using Quantity One analysis software version 4.6.7 (basic) (Bio-Rad, UK).

Leptin, hepcidin and IL-6 ELISAs. The secretomes from the SW480 cells, the PAS (control) and the DASs, were all assessed for leptin, hepcidin and IL-6 using ELISA. Human IL-6 Quantikine ELISA and human leptin Quantikine ELISA (D6050 and DLP00, respectively; R\&D Systems) were carried out according to the manufacturer's instructions. For the hepcidin ELISA, the secretomes were extracted using the S-500 extraction kit (Peninsula Laboratories, Belmont, CA, USA) and then, the hepcidin levels were quantified using peptide enzyme immunoassay (S-1328.0001; Peninsula Laboratories, Belmont, CA, USA) using protocol IV from the manufacturer's instructions. The leptin and IL-6 ELISAs were similarly used to assess the levels in the human serum samples according to the manufacturer's instructions. However, the hepcidin levels in the human serum samples were assessed using a mass spectrometry-based Hepcidin assay described below. The levels of transferrin and haemoglobin in the human samples were assessed by the Biochemistry Department (University Hospitals Birmingham NHS Foundation Trust).

Serum hepcidin assay. The sera were diluted 1 to 5 in $8 \mathrm{M}$ urea (Sigma-Aldrich), 1\% CHAPS (Sigma-Aldrich), $25 \mathrm{mM}$ ammonium bicarbonate (Sigma-Aldrich) and $50 \mathrm{ng} / \mathrm{ml}$ stable isotope labelled synthetic HEP25 (Alta Bioscience, Birmingham, UK) was added. The samples were then diluted 10 -fold in $25 \mathrm{mM}$ ammonium bicarbonate and $100 \mu 1$ applied to $\mathrm{Cu}^{2+}$ loaded IMAC ProteinChip arrays (Bio-Rad, Dalkeith, UK). Following washing with $25 \mathrm{mM}$ ammonium bicarbonate sample spots were coated with saturated sinapinic acid (Sigma-Aldrich) and analysed using an ultraflextreme MALDI (Bruker, Germany) instrument in linear mode. Hepcidin concentrations were calculated from the peak intensity ratio of endogenous/exogenous hepcidin (at $\mathrm{m} / \mathrm{z} 2790.4$ and 2800.4, respectively).

Ferrozine assay for iron quantification. The SW480 cells were co-cultured with IL-6 or leptin as above-mentioned. At the end of the culture period, the cells were lysed in HEPES-saline lysis buffer [150 $\mu 1,10 \mathrm{mM}, \mathrm{pH} 7.4, \mathrm{NaCl} 0.9 \%$ (w/v)]. A ferrozine stock solution was prepared by mixing sodium acetate $(17 \mathrm{mM}, 13.8 \mathrm{~g})$, L-sodium ascorbate $(4.6 \mathrm{mM}, 0.91 \mathrm{~g})$ and 3-(2-pyridyl)-5,6-diphenyl-1,2,4-triazine-p,p'-disulfonic acid monosodium salt hydrate $(0.18 \mathrm{mM}, 0.09 \mathrm{~g})$ (all Sigma-Aldrich) into DI $\mathrm{H}_{2} \mathrm{O}(122 \mathrm{ml})$. The cell lysate was thoroughly mixed and $90 \mu \mathrm{l}$ was aspirated and mixed with a trichloroacetic solution $[200 \mu \mathrm{l}, 20 \%(\mathrm{w} / \mathrm{v})]$, which was then heated at $100^{\circ} \mathrm{C}$ for $10 \mathrm{~min}$ and then centrifuged at $12,000 \mathrm{rpm}$ for $5 \mathrm{~min}$ to pellet the protein precipitate. The supernatant was aspirated and $200 \mu 1$ was added to $600 \mu 1$ ferrozine stock solution and mixed thoroughly and the absorbance was read on a plate reader at $\lambda=550 \mathrm{~nm}$. All results were standardised to protein content using a protein assay kit (Thermo Fisher Scientific).

\section{Statistical analysis}

In vitro analyses. For the majority of analyses it is necessary to perform Mann-Whitney U tests to determine the equality of medians on the unmatched data as this test requires no assumptions regarding the data distributions or variances. Unpaired 2 sample t-tests were performed, following normality and equal variance testing and in instances where variances were not determined, the unequal option in Stata was invoked.

Serum analyses. Three subcategories of patient data were used for subsequent analysis: patients with no abnormality $(n=51)$, patients with polyps $(n=90)$ and adenocarcinoma patients $(n=22)$. In order to measure the strength and direction of association that exists between the parameters of interest [haemoglobin (Hb), BMI, leptin, IL-6 and hepcidin] Kendall's Tau-b correlation coefficients were calculated. This nonparametric method was selected as, although the parameter data is continuous in structure, the data are not normally distributed and sample sizes are relatively small for some patient subcategories (e.g. adenocarcinoma, $\mathrm{n}=22$ ). Scatter plots and linear prediction plots were produced to allow visualisation of the relationships between parameters.

To determine significant differences in mean measurements between the patient subcategories, regression analyses were performed as the underlying assumptions of normality, homogeneity of variance and equal sample sizes were unmet in the data tested and to avoid multiplicity in testing. Dummy variables were employed for each subcategory within the regression. Wald tests were subsequently performed after each regression to complete the comparison analysis. A significance level of 5\% was used throughout. Statistical analyses were performed using Stata software version 12.1 (StataCorp, College Station, TX, USA).

\section{Results}

Validation of an in vitro adipocyte culture model. Initially an in vitro model of human adipocytes was established and analysis performed to determine whether these mature adipocytes were 

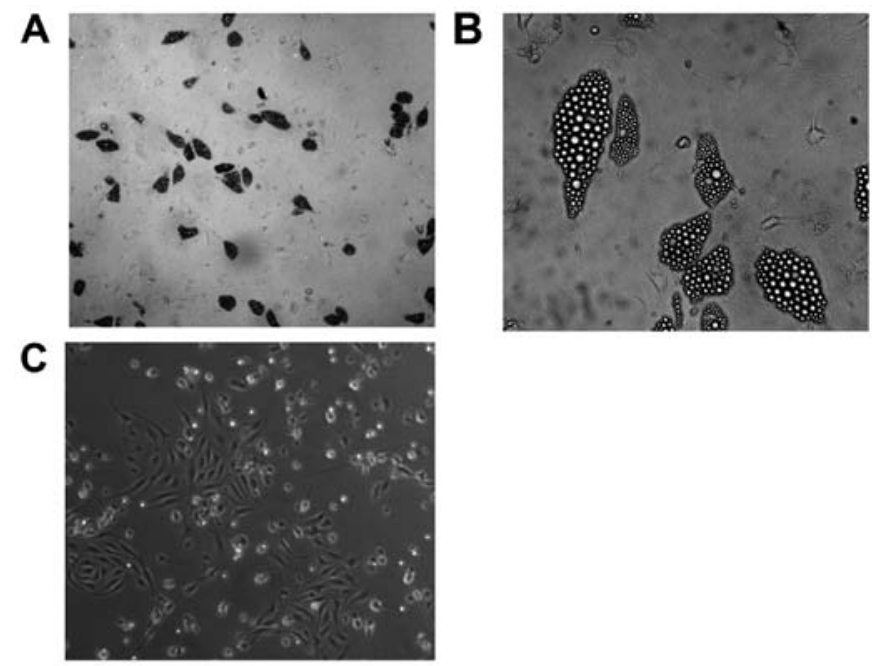

D

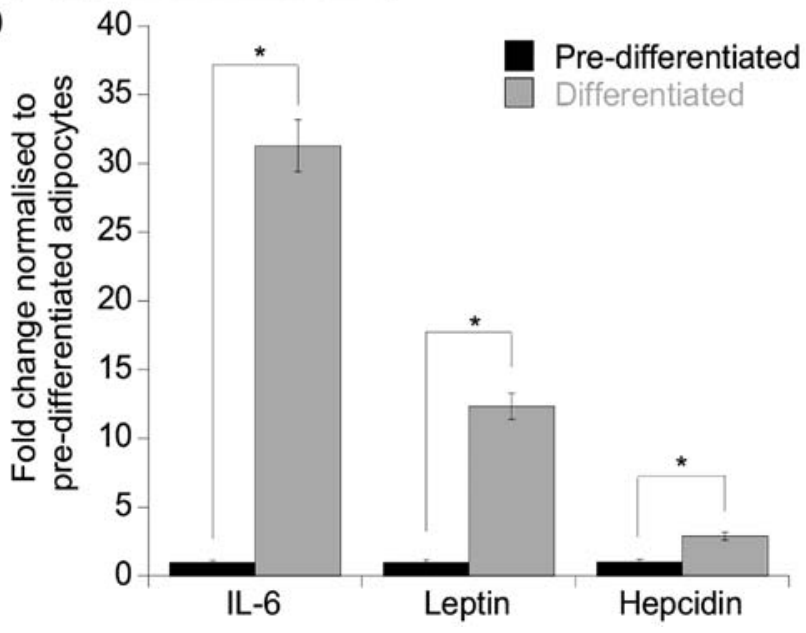

Figure 1. Brightfield images of adipocytes and quantification of IL-6, leptin and hepcidin in adipocyte secretome. (A) Mature human adipocytes ( $\mathrm{x} 4$ magnification). (B) Mature human adipocytes with evidence of lipid filled vesicles (x20 magnification). (C) Immature preadipocytes (x10 magnification). (D) Fold change in the secreted levels of IL-6, leptin and hepcidin in DAS compared to PAS, the latter normalised to 1 . Error bars denote \pm SEM with " indicating statistical significance $(\mathrm{p}<0.05, \mathrm{n}=3)$. DAS, differentiated adipocyte secretome; PAS, predifferentiated adipocyte secretome.

functional. The cultured human adipocytes were characteristic of mature differentiated adipocytes as indicated by the abundance of lipid filled vesicles (Fig. 1A and B) compared to the preadipocytes (control) (Fig. 1C). To assess whether these adipocytes were able to secrete adipokines, an antibody array was performed on the DAS and initial screening indicated that an array of adipokines/cytokines was expressed including IL-6, leptin, ENA-78, IL-8, PAI-1 and Ang-2 (data not shown). To further accurately quantitate the levels of IL-6, leptin and hepcidin, separate ELISAs were performed on the secretomes and as anticipated, both leptin and IL- 6 were increased by 29- and 12-fold, respectively compared to the undifferentiated control secretomes (leptin, $\mathrm{p}=0.05$; IL-6, $\mathrm{p}=0.04$ ). Furthermore, hepcidin was also increased 3 -fold compared to the control $(\mathrm{p}=0.05)($ Fig. 1D).

Effect of the adipocyte secretome on colonocyte cell viability and proliferation. Assessment of the viability and of the proliferation of the colorectal cancer cell line SW480 was
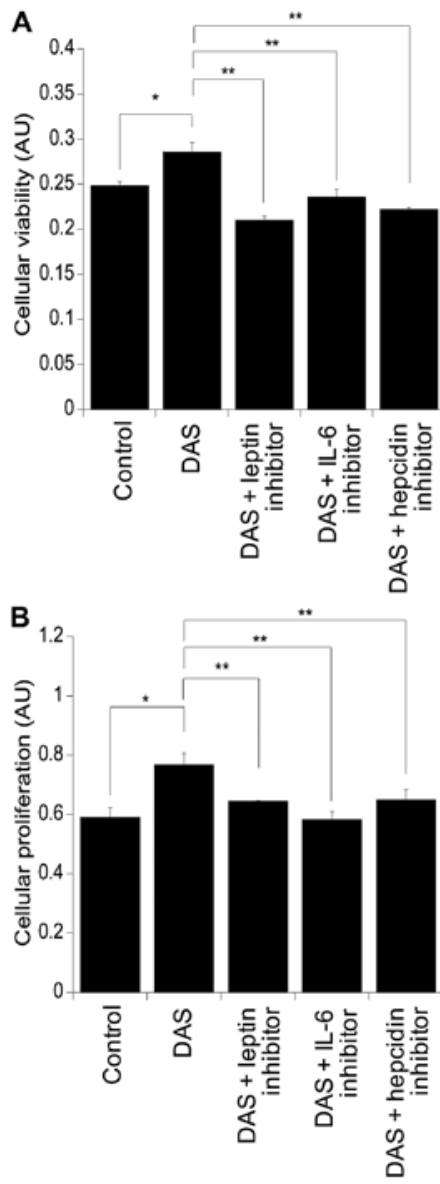

Figure 2. Cell viability and proliferation of colorectal carcinoma SW480 cells challenged with either DAS, \pm leptin, IL- 6 or hepcidin inhibitors Controls included cells in preadipocyte secretome. Cells were then subjected to (A) assessment forcellular viability by an MTT assay and (B) cellular proliferation using a BrdU assay. Error bars denote \pm SEM and $n=3$. Statistical significance is denoted by ${ }^{*}$ and ${ }^{* *}$ which represent $\mathrm{p}<0.05$ and $\mathrm{p}<0.005$ respectively, when compared to the control. DAS, differentiated adipocytes secretome.

performed using MTT and BrdU assays, respectively (Fig. 2). Following culture with DAS there was a significant increase in cellular viability compared to cells challenged with the control alone $(\mathrm{p}=0.02)$ (Fig. 2A). This was also mirrored at the level of cellular proliferation ( $\mathrm{p}=0.03$ ) (Fig. 2B). Supplementation of DAS with leptin, IL-6 and hepcidin inhibitors resulted in suppression of cellular viability compared to DAS alone: DAS with leptin inhibitor, $\mathrm{p}=0.002$; DAS with IL-6 inhibitor, $\mathrm{p}=0.002$; and DAS with hepcidin inhibitor, $\mathrm{p}=0.0008$. Similar findings were observed in the levels of cellular proliferation, resulting in suppression in cultures supplemented with the inhibitors compared to those with DAS alone: DAS with leptin inhibitor, $\mathrm{p}=0.007$; DAS with IL-6 inhibitor, $\mathrm{p}=0.0005$; and DAS with hepcidin inhibitor, $\mathrm{p}=0.009$ (Fig. 2B).

To further clarify the role of IL-6, leptin and hepcidin in colonocyte viability, all three factors were supplemented into basal growth medium. Challenging the SW480 cells with either IL-6 $(\mathrm{p}=0.003)$, leptin $(\mathrm{p}=0.01)$ or hepcidin $(\mathrm{p}=0.01)$ resulted in significant increases in colonocyte viability and as expected, incubation with the respective inhibitor reversed the pro-viability effect back to basal levels in all cases: IL-6 with IL-6 inhibitor, $p=0.005$; leptin with leptin inhibitor, $p=0.003$; and hepcidin with hepcidin inhibitor, $\mathrm{p}=0.05$ (Fig. 3). 


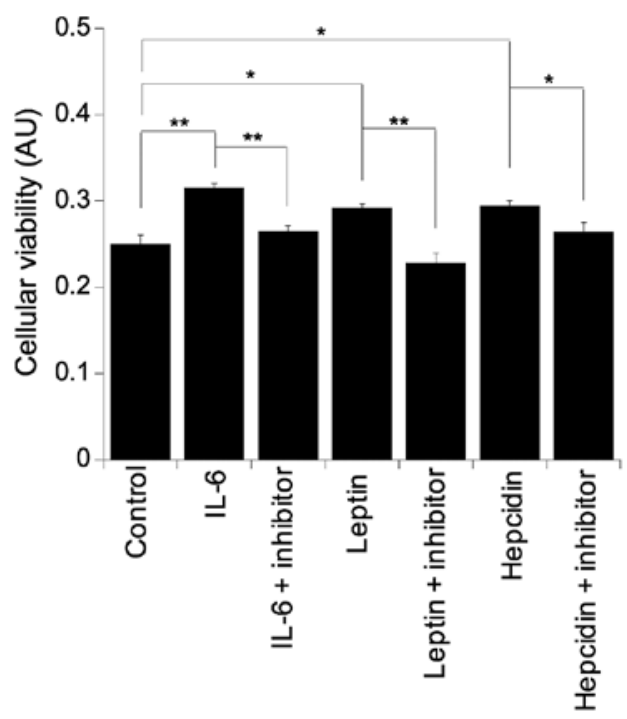

Figure 3. Cell viability of the colorectal carcinoma SW480 cells challenged with either, IL-6, leptin or hepcidin \pm the respective inhibitor. The control cells were grown in growth medium alone. The cells were then subjected to assessment for cellular viability by an MTT assay. Error bars denote \pm SEM and $n=3$. Statistical significance denoted by ${ }^{*}$ and ${ }^{* *}$ which represent $\mathrm{p}<0.05$ and $\mathrm{p}<0.005$ respectively, when compared to the control.

Complex interplay between IL-6, leptin and hepcidin. To determine whether these three factors regulate the expression of each other, each individual factor was supplemented into culture medium and the levels of the other two factors were evaluated (Fig. 4). Challenging with IL-6 or hepcidin significantly elevated colonocyte secreted leptin $(\mathrm{p}=0.05)$. Similarly, challenging with leptin or hepcidin resulted in elevated levels of colonocyte secreted IL-6 ( $\mathrm{p}=0.05$ ) (Fig. 4B). Furthermore, it was found that IL- 6 and leptin markedly elevated the level of secreted hepcidin $(\mathrm{p}=0.05)$ (Fig. 4C).

Leptin and IL-6-induced cellular viability and proliferation were blocked by hepcidin inhibition. To ascertain whether the previously observed leptin and IL-6-mediated increases in cellular proliferation were, in part, a function of hepcidin action, the SW480 cells were challenged with leptin or IL-6 in the presence or absence of the hepcidin antagonist (Fig. 5A).

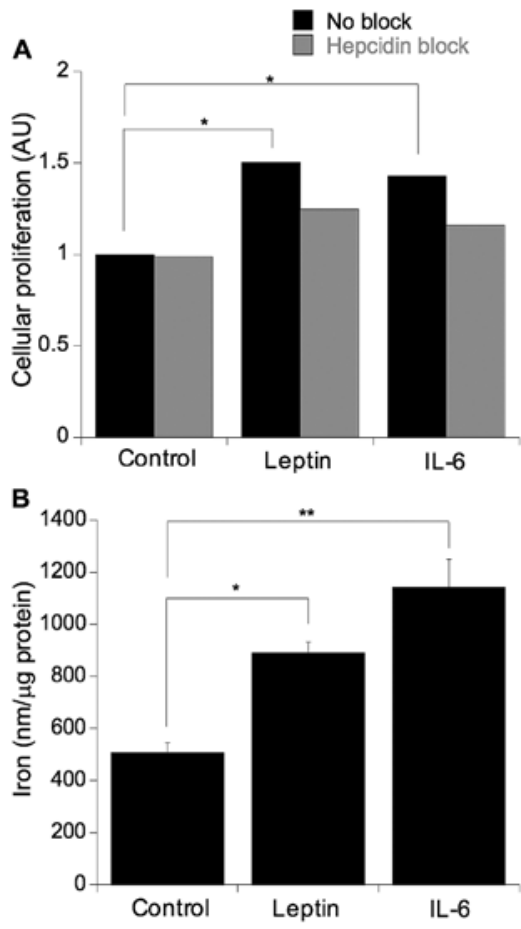

Figure 5. Proliferation and cellular iron content of the SW480 cells after adipokine challenge. (A) The SW480 cells were challenged with either leptin or IL-6 in the presence or absence of the hepcidin antagonist. The control cells were grown in growth medium alone. Cells were then subjected to assessment for cellular viability by an MTT assay. (B) The SW480 cells were challenged with leptin or IL-6 in the presence of iron (ferrous sulphate). The control cells were grown in growth medium supplemented with iron alone. The cells were then subjected to assessment of total cellular iron concentrations using a ferrozine assay. Error bars denote \pm SEM and $n=3$. Statistical significance is denoted by ${ }^{*}$ and ${ }^{* *}$ which represent $\mathrm{p}<0.05$ and $\mathrm{p}<0.005$ respectively, when compared to the control.

As expected, leptin and IL- 6 both significantly increased cellular proliferation (leptin, $\mathrm{p}=0.05$; IL- $6, \mathrm{p}=0.03$ ) and this induction was ablated with the addition of the hepcidin antagonist, indicated by a non-statistically significant difference in mean values ( $\mathrm{p}=0.81$ ) (Fig. 5A). To further assess whether the proliferative effect of leptin and IL-6 impact on cellular iron metabolism, the cells were cultured in the presence of either IL- 6 or leptin and the levels of cellular iron were deter-
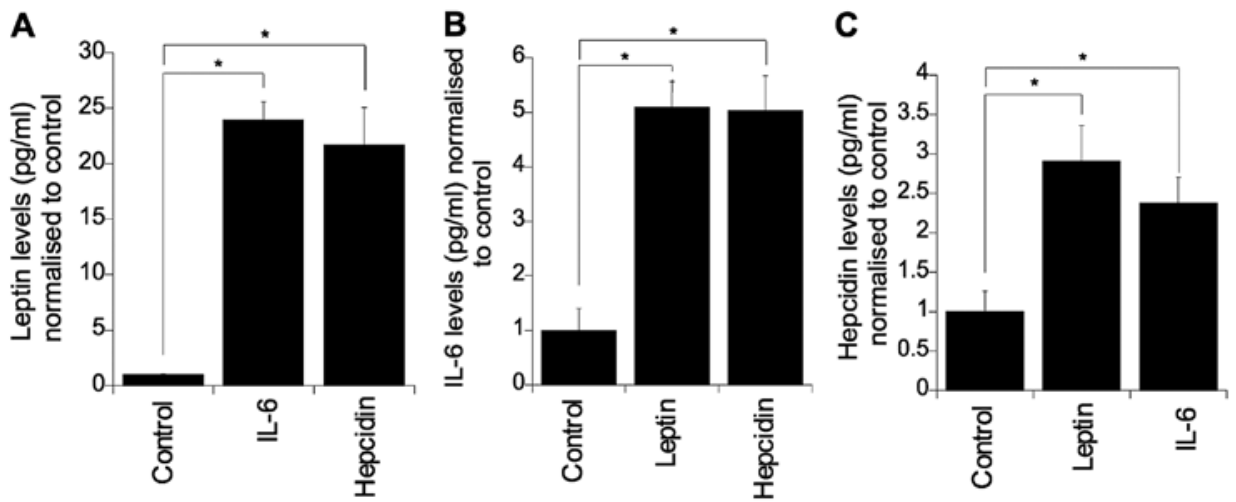

Figure 4. Quantification of leptin, IL-6 or hepcidin in the conditioned medium of the SW480 cells after being challenged with either leptin, IL-6 or hepcidin . (A) IL-6 or hepcidin challenge and the levels of leptin measured compared to non-stimulated cells. (B) Leptin or hepcidin challenge and the levels of IL-6 measured compared to control. (C) Leptin and IL- 6 challenge and the levels of hepcidin measured compared to control. Error bars denote \pm SEM and statistical significance $(\mathrm{n}=3)$ is denoted by ${ }^{*}$ which represents $\mathrm{p}<0.05$, compared to the control. 
Table I. Human serum sample analysis.

\begin{tabular}{lcccccc}
\hline & $\begin{array}{c}\text { Age } \\
(\text { years })\end{array}$ & $\begin{array}{c}\text { BMI } \\
\left(\mathrm{kg} / \mathrm{m}^{2}\right)\end{array}$ & $\begin{array}{c}\mathrm{Hb} \\
(\mathrm{g} / \mathrm{dl})\end{array}$ & $\begin{array}{c}\text { Hepcidin } \\
(\mathrm{ng} / \mathrm{ml})\end{array}$ & $\begin{array}{c}\mathrm{IL}-6 \\
(\mathrm{ng} / \mathrm{ml})\end{array}$ & $\begin{array}{c}\text { Leptin } \\
(\mathrm{ng} / \mathrm{ml})\end{array}$ \\
\hline Mean & 63 & 29.76 & 14.51 & 36 & 26.3 & 2.01 \\
SD & $60-73$ & 5.5 & 1.4 & 14 & 18.3 & 1.6 \\
\hline
\end{tabular}

Means \pm standard deviations (SD) of BMI, IL-6, leptin, hepcidin and haemoglobin in human serum samples $(n=163)$. BMI, body mass index; IL-6, interleukin-6; Hb, haemoglobin.

mined (Fig. 5B). Culturing with either IL-6 or leptin resulted in an induction in cellular iron levels (IL-6, $\mathrm{p}=0.0007$; leptin, $\mathrm{p}=0.01)$.

Relationship between BMI, IL-6, leptin and hepcidin in human serum samples. To investigate the relationship between human clinical obesity $\left(\mathrm{BMI} \geq 30 \mathrm{~kg} / \mathrm{m}^{2}\right)$, IL-6, leptin and hepcidin, 163 well-characterised human serum samples were collected from patients undergoing colonoscopy for suspected colonic disease. Table I reports the means and standard deviations of the combined patient data for BMI, leptin, IL-6, hepcidin and haemoglobin.

Investigating the combined data of the 163 patients, there were correlations between BMI and IL-6 (Kendall's Tau-b=0.14, $\mathrm{p}=0.01$ ), BMI and leptin (Kendall's Tau-b=0.42, $\mathrm{p}<0.001$ ) and BMI and hepcidin (Kendall's Tau-b=-0.10, $\mathrm{p}=0.05)$. Serum hepcidin did not correlate with IL-6 or leptin, but did positively correlate with haemoglobin levels (Kendall's Tau-b $=0.15, \mathrm{p}<0.001)$. In addition, there was a positive correlation between leptin and IL-6 (Kendall's Tau-b=0.10, $\mathrm{p}=0.05$ ) (Table II). Subanalyses were also performed on patient samples with: no disease, presence of polyps and presence of adenocarcinoma. In the group with no disease the only positive correlation was between hepcidin and haemoglobin (Kendall's Tau-b=0.34, $\mathrm{p}=0.03$ ). In the group with polyps, positive correlations were observed for BMI and leptin (Kendall's Tau-b=0.4, $\mathrm{p}<0.001$ ) and hepcidin with haemoglobin (Kendall's Tau-b=0.17, $\mathrm{p}=0.03$ ). Finally, in the adenocarcinoma group, hepcidin correlated with haemoglobin (Kendall's Tau-b=0.34, $\mathrm{p}=0.03$ ). Scatter plots were produced to visualise the data (not included) with one interesting relationship observed between leptin and hepcidin in the adenocarcinoma patient subcategory (Fig. 6). Although no statistically significant correlation was determined (Kendall's Tau-b=0.24, $\mathrm{p}=0.127$ ), the plot reveals a possible different trend (positive) in this group of patients in comparison with the data from the polyp- and no abnormality-patient data. However, due to the small sample size $(n=22)$ further investigation is necessary to determine if this observation is a real trend in this patient group or artefactual.

Finally, regression analysis was used to compare the mean levels of BMI, Hb, hepcidin, IL-6 and leptin in the various groups. Results indicated that the BMI was significantly lower in the adenocarcinoma group compared to the normal and polyp groups $(\mathrm{p}=0.03$ and $\mathrm{p}=0.01$, respectively) (Table III). Haemoglobin in the polyp group
Table II. Correlations in human serum samples.

\begin{tabular}{|c|c|c|c|c|c|}
\hline & $\mathrm{Hb}$ & BMI & Leptin & IL-6 & Hepcidi \\
\hline \multicolumn{6}{|c|}{ All patients $(n=163)$} \\
\hline $\mathrm{Hb}$ & 1.00 & - & - & - & - \\
\hline BMI & $\begin{array}{l}-0.07 \\
(0.15)\end{array}$ & $\begin{array}{c}1.00 \\
-\end{array}$ & - & - & \\
\hline Leptin & $\begin{array}{l}-0.11^{\mathrm{a}} \\
(0.03)\end{array}$ & $\begin{array}{c}0.42^{\mathrm{a}} \\
(<0.001)\end{array}$ & 1.00 & - & - \\
\hline IL-6 & $\begin{array}{l}-0.05 \\
(0.36)\end{array}$ & $\begin{array}{c}0.14^{\mathrm{a}} \\
(0.01)\end{array}$ & $\begin{array}{c}0.10 \\
(0.05)\end{array}$ & 1.00 & - \\
\hline Hepcidin & $\begin{array}{c}0.15^{\mathrm{a}} \\
(<0.001)\end{array}$ & $\begin{array}{l}-0.10^{\mathrm{a}} \\
(0.05)\end{array}$ & $\begin{array}{l}-0.01 \\
(0.78)\end{array}$ & $\begin{array}{l}-0.07 \\
(0.14)\end{array}$ & 1.0 \\
\hline
\end{tabular}

No abnormality $(\mathrm{n}=51)$

$\mathrm{Hb}$

BMI

$-0.21$

$(0.19)$

Leptin

0.05

(0.76)

0.06

IL-6

0.1

$(0.72)$

Hepcidin

(0.55)

0.07

(0.67)

1.0

Hepcidin

$\begin{array}{cc}0.34^{\mathrm{a}} & -0.08 \\ (0.03) & (0.63)\end{array}$

0.24

0.16

(0.13) (0.31)

1.0

Polyps (n=39)

$\begin{array}{lccccc}\mathrm{Hb} & 1.0 & - & - & - & - \\ \mathrm{BMI} & 0.02 & 1.0 & - & - & - \\ & (0.77) & & & - & - \\ \text { Leptin } & -0.08 & 0.40^{\mathrm{a}} & 1.0 & - & - \\ & (0.31) & (<0.001) & & & \\ \text { IL-6 } & -0.05 & 0.10 & -0.03 & 1.0 & - \\ & (0.51) & (0.20) & (0.70) & & \\ \text { Hepcidin } & 0.17^{\mathrm{a}} & -0.12^{\mathrm{a}} & 0.008 & -0.11 & 1.0 \\ & (0.03) & (0.12) & (0.92) & (0.16) & 1.0\end{array}$

Adenocarcinoma $(\mathrm{n}=73)$

$\mathrm{Hb}$

1.0

BMI

0.21

1.0

Leptin

$(0.19)$

IL-6

0.05

0.06

(0.72)

0.1

(0.55)

0.07

(0.67)

Hepcidin

0.34

$-0.08$

$(0.3)$

(0.63)

$-0.15$

$(0.34)$

0.24

$(0.13) \quad(0.31)$

1.0

0.16

1.0

Kendall's Tau-b correlation coefficients for sera collected from all patients $(n=163)$ and the subsets thereof; no abnormality $(n=51)$, polyps $(n=39)$ and adenocarcinoma $(n=73)$. Top row represents Kendall's Tau-b correlation coefficients with the bottom row in parenthesis denoting the P-value ( $\left.{ }^{\mathrm{a}} \mathrm{p}<0.05\right)$. BMI, body mass index; IL-6, interleukin-6; $\mathrm{Hb}$, haemoglobin.

was higher than that in the normal group $(\mathrm{p}=0.001)$ and the adenocarcinoma group $(\mathrm{p}<0.001)$. The latter likely explains why there is also a concomitant decrease in hepcidin levels in the adenocarcinoma group compared to the polyp 


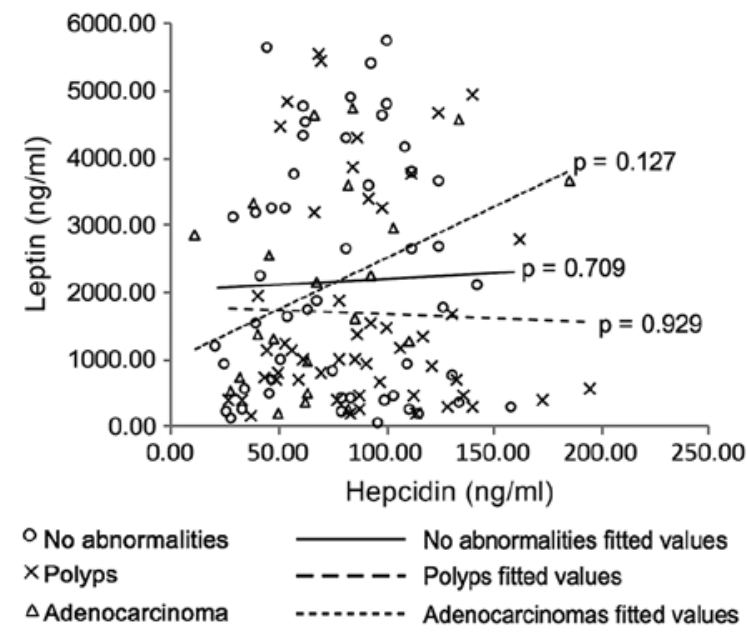

Figure 6. Association of leptin and hepcidin levels in sera from patients with i) no abnormalities (O), ii) polyps (x) and iii) adenocarcinoma $(\Delta)$.

Table III. Mean levels of BMI, Hb, IL-6 and leptin in the subdivided groups.

\begin{tabular}{lllclc}
\hline Groups & $\begin{array}{c}\mathrm{BMI} \\
\left(\mathrm{kg} / \mathrm{m}^{2}\right)\end{array}$ & $\begin{array}{c}\mathrm{Hb} \\
(\mathrm{g} / \mathrm{dl})\end{array}$ & $\begin{array}{c}\text { Hepcidin } \\
(\mathrm{ng} / \mathrm{ml})\end{array}$ & $\begin{array}{c}\mathrm{IL}-6 \\
(\mathrm{ng} / \mathrm{ml})\end{array}$ & $\begin{array}{c}\text { Leptin } \\
(\mathrm{ng} / \mathrm{ml})\end{array}$ \\
\hline Normal & 29.4 & 14.24 & 79.37 & 24.74 & 2167 \\
Polyps & 29.47 & $14.96^{\mathrm{a}}$ & 91.64 & 21.94 & 1752 \\
$\begin{array}{l}\text { Adeno- } \\
\text { carcinoma }\end{array}$ & $27.41^{\mathrm{a}, \mathrm{b}}$ & $13.95^{\mathrm{b}}$ & $72.0^{\mathrm{b}}$ & $34.73^{\mathrm{a}, \mathrm{b}}$ & 2091 \\
\hline
\end{tabular}

Normal $(n=51)$, polyp $(n=39)$ and adenocarcinoma $(n=73)$ groups Statistical significance is denoted by ${ }^{a}$ and ${ }^{b}$ which represent $\mathrm{p}<0.05$ when compared to the polyp and to normal group, respectively.

group $(\mathrm{p}=0.04)$. Consistent with previous data, IL-6 was significantly elevated in the adenocarcinoma group compared to the polyp and normal groups $(\mathrm{p}=0.0001$ and $\mathrm{p}=0.003$, respectively).

\section{Discussion}

Obesity is increasingly associated with risk and progression of colorectal tumourigenesis; however, the underlying mechanism remains to be elucidated. Previous studies have revealed that obesity is linked with increased circulating levels of IL-6 (11-13) and leptin (7-9) and indeed, this was also observed in our entire cohort of patients where BMI is highly correlated with circulating IL-6 and leptin. In the present study we revealed, as previous studies have, that human adipose tissue is a highly metabolically active organ secreting a plethora of adipokines/cytokines.

Notably, we demonstrated that in vitro primary mature human adipocytes, isolated from the greater omentum, secrete hepcidin along with the expected molecules IL-6 and leptin. This is consistent with the studies of Bekri et al (22) which demonstrated that human adipose tissue expresses hepcidin mRNA. The trigger for hepcidin expression in adipose tissue is unclear, although previous studies have implicated IL-6 and hypoxia $(22,28)$. The net effect of hepcidin expression in adipose tissue is likely to be multifaceted and may explain the associated poor iron status and low grade anaemia of chronic disease observed in obese individuals (22-24). This is illustrated in a study of patients undergoing bariatric surgery, where weight loss was associated with decreased serum hepcidin and improved functional iron profile (29). This association of systemic hepcidin with body iron status is further supported by our own patient data which reveal that hepcidin levels are related to haemoglobin levels.

However, our study indicated that adipocytes can secrete a complex cocktail of factors which may also impact systemically on colorectal epithelial cells. Notably, we indicated that leptin, IL-6 and hepcidin can all increase colonocyte cell viability. Previous studies revealed that leptin may induce tumour angiogenesis, reduce apoptosis, promote cell growth and migration of colon cancer cells in vitro $(8,30,31)$, although, an in vivo murine study failed to show that leptin alone can drive intestinal tumourigenesis (8). This is consistent with a prospective nested case-control study within the European Prospective Investigation into Cancer and Nutrition (EPIC) cohort (32). Conversely, other human epidemiological studies have indicated a role for leptin in colorectal tumourigenesis (7,33-34). Thus, the role of leptin in colorectal carcinogenesis remains unclear.

Several studies reported an association between elevated levels of circulating IL-6 with the presence and stage of colorectal cancer; this is consistent with our observation that IL-6 is increased in the serum of cancer patients $(11,35,36)$. The increased levels of IL- 6 may be a consequence of adipose-derived secretion of IL-6, low-grade chronic inflammation or perhaps due to the elevated IL-6 secretion by the tumour. Furthermore, in vitro studies demonstrated that challenging colorectal cell lines with IL-6 does induce a more aggressive phenotype, including features such as anchorage-independent growth and increased invasiveness $(12,36)$.

Additionally, in the present study we demonstrated that hepcidin can promote colonocyte cellular viability. The importance of hepcidin in modulating colonocyte cell fate is further supported by our data, which demonstrated that leptin and IL-6 mediated increases in colonocyte proliferation appear to be hepcidin dependent. This is exemplified by a complete abolishment in leptin/IL-6 effects in the presence of a previously described hepcidin antagonist (27). It is clear from our data that challenging the SW480 cells with IL- 6 or leptin results in increased hepcidin expression. Whilst this may be expected in adipocytes and hepatocytes $(14,15)$, this is the first time that such an observation has been made in the context of a tissue which does not express hepcidin endogenously. These observations may well shed light on previous studies which reveal de novo cancer tissue expression of hepcidin (18,37-39).

We predicted that local tumoural hepcidin expression in the colon, as previously reported (18), is likely to be a consequence of either local or systemic IL-6 and/or leptin, the latter being directly influenced by the extent of adiposity. Whether this pool of hepcidin contributes to systemic hepcidin is unclear, though from the serum analyses in the cancer group, hepcidin was actually suppressed compared to the polyp group. As such, it is likely that this reflects the significant suppression in haemoglobin in the cancer group in comparison to the polyp group. 
Irrespective of the mechanism by which colorectal cancer cells express hepcidin, the net effect is likely to be a rise in intracellular iron; a consequence of a hepcidin mediated loss of ferroportin (25) and this is likely to impact in a plethora of ways including increasing the rate of DNA synthesis (as a consequence of iron being a rate limiting factor in the function of ribonucleotide function), ATP generation and cell cycle (40). In addition, in vitro and in vivo studies revealed that excess cellular iron amplifies the Wnt signalling and intestinal tumourigenesis $(21,22)$.

In conclusion, our study confirmed that adipose tissue is a metabolically active organ which secretes leptin, IL-6 and hepcidin. Notably the expression of colonocyte IL-6, leptin and hepcidin are all interlinked. However, it is likely that hepcidin is central to the process of tumourigenesis allowing excess cellular iron to amplify Wnt signalling. A mechanism of ablating de novo tissue hepcidin expression may prove to be a novel platform for therapeutic intervention in obesity driven colorectal tumourigenesis in this patient group.

\section{Acknowledgements}

We gratefully acknowledge the contribution to this study made by the University of Birmingham's Human Biomaterials Resource Centre which has been supported by the Birmingham Science City and the Experimental Medicine Network of Excellence project. We wish to acknowledge the grant support from the World Cancer Research Fund (2009/SD04) for funding this study.

\section{References}

1. Arnold M, Pandeya N, Byrnes G, Renehan PAG, Stevens GA Ezzati PM, Ferlay J, Miranda JJ, Romieu I, Dikshit R, et al: Global burden of cancer attributable to high body-mass index in 2012: A population-based study. Lancet Oncol 16: 36-46, 2015.

2. Protani M, Coory M and Martin JH: Effect of obesity on survival of women with breast cancer: Systematic review and meta-analysis. Breast Cancer Res Treat 123: 627-635, 2010.

3. Onstad MA, Schmandt RE and Lu KH: Addressing the role of obesity in endometrial cancer risk, prevention, and treatment. J Clin Oncol 34: 4225-4230, 2016.

4. Larsson SC and Wolk A: Obesity and colon and rectal cancer risk: A meta-analysis of prospective studies. Am J Clin Nutr 86 : 556-565, 2007.

5. Moghaddam AA, Woodward M and Huxley R: Obesity and risk of colorectal cancer: A meta-analysis of 31 studies with 70,000 events. Cancer Epidemiol Biomarkers Prev 16: 2533-2547, 2007.

6. Considine RV, Sinha MK, Heiman ML, Kriauciunas A, Stephens TW, Nyce MR, Ohannesian JP, Marco CC, McKee LJ, Bauer TL, et al: Serum immunoreactive-leptin concentrations in normal-weight and obese humans. N Engl J Med 334: 292-295, 1996

7. Stattin P, Lukanova A, Biessy C, Söderberg S, Palmqvist R, Kaaks R, Olsson T and Jellum E: Obesity and colon cancer: Does leptin provide a link? Int J Cancer 109: 149-152, 2004.

8. Chia VM, Newcomb PA, Lampe JW, White E, Mandelson MT, McTiernan A and Potter JD: Leptin concentrations, leptin receptor polymorphisms, and colorectal adenoma risk. Cancer Epidemiol Biomarkers Prev 16: 2697-2703, 2007.

9. Jaffe T and Schwartz B: Leptin promotes motility and invasiveness in human colon cancer cells by activating multiple signal-transduction pathways. Int J Cancer 123: 2543-2556, 2008.

10. Fenton JI, Hord NG, Lavigne JA, Perkins SN and Hursting SD: Leptin, insulin-like growth factor-1, and insulin-like growth factor-2 are mitogens in $\mathrm{Apc}^{\mathrm{Min} /+}$ but not $\mathrm{Apc}^{+/+}$colonic epithelial cell lines. Cancer Epidemiol Biomarkers Prev 14: 1646-1652, 2005.
11. Knüpfer H and Preiss R: Serum interleukin-6 levels in colorectal cancer patients - a summary of published results. Int J Colorectal Dis 25: 135-140, 2010.

12. Fenton JI, Hursting SD, Perkins SN and Hord NG: Interleukin-6 production induced by leptin treatment promotes cell proliferation in an $\mathrm{Apc}^{\mathrm{Min} / \mathrm{+}}$ colon epithelial cell line. Carcinogenesis 27: 1507-1515, 2006.

13. Becker C, Fantini MC, Schramm C, LehrHA, Wirtz S, Nikolaev A, Burg J, Strand S, Kiesslich R, Huber S, et al: TGF-beta suppresses tumor progression in colon cancer by inhibition of IL- 6 transsignaling. Immunity 21: 491-501, 2004.

14. Chung B, Matak P, McKie AT and Sharp P: Leptin increases the expression of the iron regulatory hormone hepcidin in $\mathrm{HuH} 7$ human hepatoma cells. J Nutr 137: 2366-2370, 2007.

15. Nemeth E, Rivera S, Gabayan V, Keller C, Taudorf S, Pedersen BK and Ganz T: IL-6 mediates hypoferremia of inflammation by inducing the synthesis of the iron regulatory hormone hepcidin. J Clin Invest 113: 1271-1276, 2004.

16. Nelson RL: Iron and colorectal cancer risk: Human studies. Nutr Rev 59: 140-148, 2001.

17. Mainous AG III, Gill JM and Everett CJ: Transferrin saturation, dietary iron intake, and risk of cancer. Ann Fam Med 3: 131-137, 2005.

18. Ward DG, Roberts K, Brookes MJ, Joy H, Martin A, Ismail T, Spychal R, Iqbal T and Tselepis C: Increased hepcidin expression in colorectal carcinogenesis. World J Gastroenterol 14: 1339-1345, 2008

19. Brookes MJ, Hughes S, Turner FE, Reynolds G, Sharma N, Ismail T, Berx G, McKie AT, Hotchin N, Anderson GJ, et al: Modulation of iron transport proteins in human colorectal carcinogenesis. Gut 55: 1449-1460, 2006.

20. Radulescu S, Brookes MJ, Salgueiro P, Ridgway RA, McGhee E, Anderson K, Ford SJ, Stones DH, Iqbal TH, Tselepis C and Sansom OJ: Luminal iron levels govern intestinal tumorigenesis after Apc loss in vivo. Cell Reports 2: 270-282, 2012.

21. Brookes MJ, Boult J, Roberts K, Cooper BT, Hotchin NA, Matthews G, Iqbal T and Tselepis C: A role for iron in Wnt signalling. Oncogene 27: 966-975, 2008.

22. Bekri S, Gual P, Anty R, Luciani N, Dahman M, Ramesh B, Iannelli A, Staccini-Myx A, Casanova D, Ben Amor I, et al: Increased adipose tissue expression of hepcidin in severe obesity is independent from diabetes and NASH. Gastroenterology 131: 788-796, 2006

23. McClung JP and Karl JP: Iron deficiency and obesity: The contribution of inflammation and diminished iron absorption. Nutr Rev 67: 100-104, 2009.

24. Tussing-Humphreys LM, Liang H, Nemeth E, Freels S and Braunschweig CA: Excess adiposity, inflammation, and iron-deficiency in female adolescents. J Am Diet Assoc 109: 297-302, 2009.

25. Nemeth E, Tuttle MS, Powelson J, Vaughn MB, Donovan A, McVey Ward D, Ganz T and Kaplan J: Hepcidin regulates cellular iron efflux by binding to ferroportin and inducing its internalization. Science 306: 2090-2093, 2004

26. Maachi M, Piéroni L, Bruckert E, Jardel C, Fellahi S, Hainque B, Capeau J and Bastard JP: Systemic low-grade inflammation is related to both circulating and adipose tissue TNFalpha, leptin and IL-6 levels in obese women. Int J Obes Relat Metab Disord 28: 993-997, 2004.

27. Kaplan J, Ward DM and De Domenico I: Identification of the hepcidin binding site on ferroportin. US Patent 8530619 B2. Filed October 26, 2007; issued September 10, 2013.

28. Andrews M and Arredondo M: Hepatic and adipocyte cells respond differentially to iron overload, hypoxic and inflammatory challenge. Biometals 25: 749-759, 2012.

29. Tussing-Humphreys LM, Nemeth E, Fantuzzi G, Freels S, Holterman AX, Galvani C, Ayloo S, Vitello J and Braunschweig C: Decreased serum hepcidin and improved functional iron status 6 months after restrictive bariatric surgery. Obesity (Silver Spring) 18: 2010-2016, 2010.

30. Aparicio T, Kotelevets L, Tsocas A, Laigneau JP, Sobhani I, Chastre $\mathrm{E}$ and Lehy T: Leptin stimulates the proliferation of human colon cancer cells in vitro but does not promote the growth of colon cancer xenografts in nude mice or intestinal tumorigenesis in $\mathrm{Apc}^{\mathrm{Min} /+}$ mice. Gut 54: 1136-1145, 2005.

31. Aleksandrova K, Nimptsch $\mathrm{K}$ and Pischon T: Obesity and colorectal cancer. Front Biosci (Elite Ed) 5: 61-77, 2013.

32. Aleksandrova K, Boeing H, Jenab M, Bueno-de-Mesquita HB, Jansen E, van Duijnhoven FJ, Rinaldi S, Fedirko V, Romieu I, Riboli E, et al: Leptin and soluble leptin receptor in risk of colorectal cancer in the European Prospective Investigation into Cancer and Nutrition cohort. Cancer Res 72: 5328-5337, 2012. 
33. Stattin P, Palmqvist R, Söderberg S, Biessy C, Ardnor B, Hallmans G, Kaaks R and Olsson T: Plasma leptin and colorectal cancer risk: A prospective study in Northern Sweden. Oncol Rep 10: 2015-2021, 2003.

34. Tamakoshi K, Toyoshima H, Wakai K, Kojima M, Suzuki K, Watanabe Y, Hayakawa N, Yatsuya H, Kondo T, Tokudome S, et al: Leptin is associated with an increased female colorectal cancer risk: A nested case-control study in Japan. Oncology 68 : 454-461, 2005.

35. Ueda T, Shimada E and Urakawa T: Serum levels of cytokines in patients with colorectal cancer: Possible involvement of interleukin- 6 and interleukin-8 in hematogenous metastasis. J Gastroenterol 29: 423-429, 1994.

36. Komoda H, Tanaka Y, Honda M, Matsuo Y, Hazama K and Takao T: Interleukin-6 levels in colorectal cancer tissues. World J Surg 22: 895-898, 1998.
37. Hsu CP, Chen YL, Huang CC, Chou CC, Liu CL, Hung CH, Kao TY and Chung YC: Anti-interleukin-6 receptor antibody inhibits the progression in human colon carcinoma cells. Eur J Clin Invest 41: 277-284, 2011

38. Kamai T, Tomosugi N, Abe H, Arai $\mathrm{K}$ and Yoshida K: Increased serum hepcidin-25 level and increased tumor expression of hepcidin mRNA are associated with metastasis of renal cell carcinoma. BMC Cancer 9: 270, 2009.

39. Pinnix ZK, Miller LD, Wang W, D'Agostino R Jr, Kute T, Willingham MC, Hatcher H, Tesfay L, Sui G, Di X, et al: Ferroportin and iron regulation in breast cancer progression and prognosis. Sci Transl Med 2: 43ra56, 2010.

40. Le NTV and Richardson DR: The role of iron in cell cycle progression and the proliferation of neoplastic cells. Biochim Biophys Acta 1603: 31-46, 2002. 